\title{
Influence of autism awareness on the psychological well-being of mothers caring for their children with autism
}

\author{
Rania A. Zaki ${ }^{* 1}$, Gehan EL Nabawy Ahmed Moawad ${ }^{2}$ \\ ${ }^{1}$ Department of Psychiatric and Mental Health Nursing, Faculty of Nursing, Ain Shams University, Egypt \\ ${ }^{2}$ Department of Pediatric Nursing, Faculty of Nursing, Mansoura University, Egypt
}

Received: March 1, 2016

DOI: $10.5430 /$ jnep.v6n9p90

\author{
Accepted: April 18, 2016 \\ Online Published: May 16, 2016 \\ URL: http://dx.doi.org/10.5430/jnep.v6n9p90
}

\begin{abstract}
Autism is currently a hot topic in the field of special education due to the high prevalence ratio of it. It is a highly variable neuro-developmental disorder that first appears during infancy or childhood and generally follows a steady course without remission. Overt symptoms gradually begin after the age of six months, become established by the age of two or three, and tend to continue through adulthood. It differs from any disabilities; the characteristics of autism generate additional stress for the parents and make the life of all the family very hard. Usually, mothers face the stressful challenges of raising a child with autism, they are concerned with their children's communication, education and related services, relationships with professionals and the independence of their children's future. Therefore, the aim of this study was to assess the influence of autism awareness on the psychological wellbeing of mothers caring for their children with autism. A descriptive research design was used. The study was conducted in two settings: the first one was the Special Needs Care Center in the Institute of post-graduate Childhood Studies which affiliated to Ain Shams University and the second one was the out-patient clinic for child psychiatric treatments at El Abassia mental health hospital. Sixty children accompanied by their mothers with certain criteria were recruited in the beginning of June 2015 to the end of August 2015. The study concluded that about two thirds of the studied sample had poor awareness regarding autism and there was a highly statistical significant relation between awareness, stress and psychological wellbeing among mothers of children with autism. The study recommended that media awareness must be increased to aid mothers in prompting tolerance and understanding of autism with a clear explanation. Furthermore, there is a necessity to counseling mothers to enhance their awareness about autism for modifying their behaviors and psychosocial skills.
\end{abstract}

Key Words: Autism, Mothers, Awareness, Stress, Psychological wellbeing

\section{INTRODUCTION}

There is agreement amongst all professionals that autism is one of the most puzzling diseases. Autism is the disorder characterized by prominent impairment in social interaction, verbal and non-verbal communication, restricted, repetitive and stereotyped behaviors or interests. The diagnosis of autism has been increased during the last fifteen years and is increasing now and it seems that it is existed not only in special races and nations but also in all social and economic groups; moreover, the possibility of to be affected by this disease in boys is four times as much as girls. ${ }^{[1]}$ Mothers of children with autism take on responsibilities of diagnosis,

\footnotetext{
*Correspondence: Rania A. Zaki; Email: d_rania1875@yahoo.com; Address: Department of Psychiatric and Mental Health Nursing, Faculty of Nursing, Ain Shams University, Egypt.
} 
advocacy, and daily care. There is evidence that this impacts upon their Quality of Life, they have a great difficulties in accepting the diagnosis of their children due to lack of knowledge, social stigma and, in establishing a healthy communication with their children to maintain their socio-emotional and physical development in a healthy way. Also, they tend to report lower quality of life, more depression, and greater pessimism about their children future than other mothers of children with other developmental disabilities. ${ }^{[2]}$ Mothers of autistic children also had higher levels of mothering stress as stress in the areas of everyday management of disruptive behaviors, heavy care giving responsibilities and concerns about the future of the child when the mothers are no longer able to care for their children. ${ }^{[3]}$ The severity of a child's autism symptoms and behaviors has consistently been found to be one of the strongest predictors of parental stress and considered an impacting factor for parental well-being. For instance, parents may receive censure and disapproval from strangers for not being able to "control" their children. ${ }^{[4]}$ Mothers are play an important and critical role in supporting their children with autism. They not only drive the decisionmaking process, they take a primary role in delivering the intervention. Consequently, they require advice, emotional support, and training in working with their children. Also, they require access to up to date and accurate information about available treatment options and support services for autism. $^{[5]}$

In addition, they also need to be supported through their social support, explaining the child's disability to others, community services, finances, and family functioning. It has assumed a great importance today to look more closely at the problems experienced not only by autistic children themselves but also their families, especially, mothers who are also affected by it, and to make determinations and inferences on the subject ensure that the parents are provided with information regarding their children problems. The mothers' role in the education and treatment of children has been documented repeatedly. Proper management of autistic children including behavior, educational, cognitive and pharmacotherapy through expanding and fortifying the autism specialized rehabilitation centers. ${ }^{[6]}$

\subsection{Significance of the problem}

Autism defined as a lifelong disorder that most of the mothers have to live and care for their children on their own forever. So, they are usually faced with difficulties and unique daily stressors associated with their children's autism disorder. ${ }^{[7]}$ Since the 1970s, there has been a dramatic rise in the number of reports documenting increasing rates of autism cases, Very few reports have been published about the occurrence of autism in Arab countries, especially those of the Middle East. ${ }^{[8]}$ In Egypt today autism is one of the biggest problems that very often under-diagnosed or more commonly, misdiagnosed, according to the latest demographic studies, there are more than 140,000 children in Egypt who suffer from autism, ${ }^{[9]}$ though an Arab Study involves two Northern African Countries (Tunisia \& Egypt), they stated that Prevalence of autism were $11.5 \%$ and $33.6 \%$ among children with developmental disabilities in Tunisia and in Egypt respectively. Another recent report estimated an overall prevalence of 1.4 ASD cases per 10,000 children in Oman. ${ }^{[10]}$ One factor that may be important to strengthen a psychological wellbeing and decreasing mothers stress are involves to being mindfully aware about the disease and of mothers negative thoughts and emotions which can lead them to negative outcomes including, physical symptoms and mental-health concerns (e.g., stress and impaired psychological wellbeing), these negative outcomes have been linked to decreased treatment gains for children with autism. The lack of mothers awareness regarding autism can lead to them failure to recognize symptom, seek diagnosis and treatment. Therefore, it is essential to assess mothers awareness regarding autism and assess their psychological wellbeing.

\subsection{Aim of the study}

The aim of this study was: To assess the influence of autism awareness on the psychological wellbeing of mothers caring for their children with autism.

\section{Research questions:}

(1) What is the awareness of mothers of children with autism?

(2) What is a psychological problem faced by mothers of children with autism?

(3) What is a psychological well-being of mothers of children with autism?

(4) Is there a relationship between mothers' awareness and psychological well-being regarding their children's autism?

\section{MeTHODS}

\subsection{Research design}

A descriptive research design was used.

\subsection{Setting}

This study was conducted in two settings: The 1st setting was the Special Needs Care Center in the Institute of Postgraduate Childhood Studies affiliated to Ain Shams University. The 2 nd setting was the out-patient clinic for child psychiatric treatments at El Abassia mental health hospital. 


\subsection{Sample}

A convenience sample of sixty children and their mothers who attended the previous mentioned setting. According to this criterion, for children with autism: Age: 1-5 years. Sex: both (males and females) and free from others neurological disorder or chronic physical disease or handicapped. For the mothers of children with autism: Doesn't have another child with any type of disabilities. Attend the previously mentioned settings regularly. Mothers who give direct care to the child.

\subsection{Tools of data collection}

The following three tools were used for data collection:

(1) A structured interviewing questionnaire developed by the researchers, based on review of recent literature under this study and concerned with the following items:

- Socio-demographic characteristics of mothers under study such as age, residence, level of education, occupational status, monthly income, the number of children.

- Characteristics of children under this study such as age, gender, birth order of the autistic child, onset, course, and duration of the disease.

- Mother's knowledge related to their awareness about their children's autism as: definition, warning signs $\&$ symptoms, predisposing factors, causes, awareness regarding care places and methods of autism which were included a speech and language therapy, social skills training, appropriate school and educational services, structured environments, occupational therapy and behavioral interventions along with medication evaluation, education about the illness and follow-up visits.

(2) Parents stress scale. It was developed by the researcher aimed to assess the extent of stress and burden on the parents' caring for Children with Autism. It consisted of 18 short statements, each item was rated on 3 points Likert scale and divided into 6 subscales as the following:

- Stress from child dependency statement no. $(1,2,3)$

- Stress from child future statement no. $(4,5,6)$

- Stress from family disharmony statement no. $(7,8,9)$

- Stress from financial cost statement no. (10)

- Stress from personal exhaustion statement no. $(11,12$, $13,14,15,16)$

- Stress from stigma statement no. $(17,18)$.

Scoring for each statement of them as following: $(0=$ no, 1 $=$ Sometimes, $2=$ yes $)$, Statements no. $(3,6,16)$ negative statement have a reverse score $(2=$ no, $1=$ Sometimes, $0=$ yes).

\subsection{Tool validity and reliability}

To achieve the criteria of trustworthiness of this tool of data collection in this study were tested and evaluated for their face and content validity, and reliability by group consisting of five experts Professors from different specialties were represented as the following: (1) professor of psychiatric medicine at Faculty of Medicine - Ain Shams University, (2) assistance professor of pediatric and psychiatric nursing from Faculty of Nursing, Al-Mansoura University, (3) professor of psychology from Medical Children Studies Department institute of Post Graduate Childhood Studies-Ain Shams University, to ascertain relevance, clarity, and completeness. The required corrections and modifications were done. The items on which the experts have agreed were included in the tools. The reliability of the tools was assessed through measuring their internal consistencies by determining Cronbach alpha coefficient (0.84).

\subsection{Psychological Well-Being Scale (PWB)}

It was defined as a parental global well-being and it was developed by Diener. ${ }^{[1]]}$ To assess the overall psychological well-being, it consisted of eight items that described important aspects of human functioning ranging from positive relationships, to feelings of competence, to having meaning and purpose in life. Each item was answered by using 7-point Likert, a self-report scale which indicate the point at which a person agrees or disagrees with each statement (7 Strongly agree, 6 Agree, 5 Slightly agree, 4 Mixed or neither agree nor disagree, 3 Slightly disagree, 2 Disagree, 1 Strongly disagree). Scores were ranged from 7 (Strong Disagreement with all items) to 56 (Strong Agreement with all items).

\subsubsection{Scoring system}

Serious discomfort: scored from (0 to 18). Moderate discomfort: scored from (19 to 37). Positive psychological strengths: score from (38 to 56). A high score represents a person with many psychological resources and strengths.

\subsubsection{Operational design}

The operational designs were included: preparatory phases, pilot study and fieldwork of the study.

- Preparatory phase: This phase was deal with the preparation of the designed data used in the collection of tools.

- Pilot study: A pilot study was conducted on 6 children with autism and their mothers for testing clarity, arrangement of content and applicability of items, also to determine time required to fill in the constructed tools of the research. Subjects who shared in the pilot study were excluded from the main study sample. 
- Field work and Procedures: The study was conducted through three months from the beginning of June 2015 to the end of August 2015. The researchers attended the waiting area of the Special Needs Care Center in the Institute of post-graduate Childhood Studies and in the out-patient clinic for child psychiatric treatments at El-Abassia mental health hospital from 9.30 am to $12.30 \mathrm{pm}$ for two days/week to collect data till the sample size reached the determined number through the three months.

\subsection{Ethical consideration}

The ethical research considerations in this study included the following:

- The necessary official approval was obtained from the director of Special Needs Care Center in the Institute of post-graduate Childhood Studies affiliated to Ain Shams University and from the director of out-patient clinic for child psychiatric treatments at El Abassia mental health hospital. Oral informed consents were secured from each subject to participate after explaining the nature, purpose, and benefits of the study.

- Subjects are allowed to choose to participate or not participates.

- Maintain confidentiality and privacy for every selected mother or child who involved on the study sample.

- Clarifying that all information will be used for scientific research only.

\subsection{Statistical design}

In the present study, a frequency analysis, using SPSS 22 that was performed to calculate the percentages, mean and stander deviation for the general characteristics of the mothers and child with autism. Chi-square and $p$-value for the relation between awareness and psychological wellbeing among mothers of children with autism.

\section{Results}

Table 1 shows that the age of more than two third $(65 \%)$ of studied children is less than five years and more than half of them $(61.7 \%)$ were boys. In relation to birth order, the ranking of $43.3 \%$ of children are the first. Concerning educational level, (38.3\%) of children was in the school of special needs while a minority $(15 \%)$ of them was in normal school. Regarding the child's age when an autism was discovered, the majority (75\%) of them are diagnosed as autistic child at one year. Finally, it was clear from this table that the condition presented with a delayed speech in $35 \%$ of children with autism.
Table 1. Number and percentage of children with autism according to their characteristics

\begin{tabular}{lll}
\hline Items & No. & \% \\
\hline Children's age (years) & 21 & 35.0 \\
$\quad 1-3$ & 39 & 65.0 \\
$3-5$ & $3.4 \pm 0.76$ & \\
Mean \pm SD & & \\
Gender & 37 & 61.7 \\
$\quad$ Males & 23 & 38.3 \\
$\quad$ Females & & \\
Birth order & 26 & 43.3 \\
$\quad$ First & 24 & 40.0 \\
Second & 6 & 10.0 \\
$\quad$ Third & 4 & 6.7 \\
$\quad$ Fourth and more & & \\
Level of education & 12 & 20.0 \\
$\quad$ Nursery & 23 & 38.3 \\
School of special needs & 9 & 15.0 \\
$\quad$ Normal school & 16 & 26.7 \\
$\quad$ Not attached to school & & \\
Onset and duration of autism & & 75.0 \\
$\quad$ 6-12 months & 45 & 20.0 \\
12 months-3 years & 12 & 5.0 \\
$\quad+3$ years & 3 & 18.3 \\
The condition presented with & & 35.0 \\
$\quad$ Loss of eye contact & 11 & 25.0 \\
Delayed speech & 21 & 21.7 \\
Tendency to play alone & 15 & \\
Inattention to mother & 13 & \\
\hline & & \\
\hline
\end{tabular}

Table 2. Number and percentage of mothers of children with autism according to their socio-demographic characteristics

\begin{tabular}{lll}
\hline Items & No. & $\%$ \\
\hline Mother's age ( years ) & 36 & 60.0 \\
$20-30$ & 20 & 33.3 \\
$30-45$ & 4 & 6.7 \\
$45+$ & $32.4 \pm 5.1$ & \\
Mean \pm SD & & \\
Mother's educational level & 4 & 6.7 \\
$\quad$ Illiterate & 3 & 5.0 \\
$\quad$ Read and write & 37 & 61.7 \\
$\quad$ Moderate education & 16 & 26.6 \\
$\quad$ Highly education & & \\
Mother's occupation & 21 & 35.0 \\
$\quad$ Working & 39 & 65.0 \\
$\quad$ Not working & & \\
Residence & 42 & 70.0 \\
$\quad$ Urban & 18 & 30.0 \\
$\quad$ Rural & & \\
Monthly income & 23 & 38.3 \\
$\quad$ Sufficient & 37 & 61.7 \\
$\quad$ Insufficient & & \\
Consanguinity & 17 & 71.7 \\
$\quad$ Yes & 43 & \\
$\quad$ No & & \\
\hline
\end{tabular}

It's evident from the Table 2 that the age of $60 \%$ of studied mothers was ranged from 20 to less than 30 years old. About two thirds $(61.7 \%)$ of studied mothers had a moderate level 
of education. Concerning mothers' occupation, the highest percentage of them $(65 \%)$ were not working. In relation to their residence, there were $(70 \%)$ of them reside in the urban area. In relation to monthly income about two thirds (61.7\%) of studied mothers have insufficient monthly income and $71.7 \%$ of studied mothers had no consanguinity.

Table 3. Number and Percentage of mothers' awareness regarding their knowledge about autism

\begin{tabular}{llc}
\hline Total score level & \multicolumn{2}{l}{ Total No. parents $=\mathbf{6 0}(\mathbf{1 0 0} \%)$} \\
\cline { 2 - 3 } & No. & $\mathbf{\%}$ \\
\hline $\begin{array}{l}\text { Good } \\
\text { (Scores } 75 \% \text { and more ) }\end{array}$ & 5 & 8.3 \\
$\begin{array}{l}\text { Average } \\
(\text { Scores 50\%-75\%) }\end{array}$ & 15 & 25 \\
$\begin{array}{l}\text { Poor } \\
(\text { Scores }<50 \%)\end{array}$ & 40 & 66.7 \\
\hline
\end{tabular}

It is observed from Table 3 that about two thirds (66.7\%) of the studied sample had poor awareness regarding their knowledge about autism followed by (25\%) had average awareness and $(8.3 \%)$ had good awareness.
Table 4 clarified that more than half of mothers of children with autism had stress about their children dependency and their children's future in the form of their worried because their children did not live normally, in addition to stress about personal exhaustion as they cannot do balance between their children needs and others family members needs and finally the stress about stigma in form of feel severe shame from their children which constitute $(55 \%, 52 \%, 51.3 \%$, and $54 \%)$ respectively.

Table 5 inferred that, the small percent $(5 \%, 2 \%, 10 \%, 5 \%$, $6 \%, 0 \%$ ) of studied mothers strongly agree about they lead a purposeful and a significant life; they engaged and interested in their daily activities; they contributing to the happiness and well-being of others, they are competent and capable in the activities that are important to them; they feel that they are good persons and live a good life; they are hopeful about their future, while $20 \%$ of them strongly agreed that their social relationships are supportive and satisfying, $68 \%$ of them strongly agreed that people respect them.

Table 4. Mothers' stress regarding care of their children with autism

\begin{tabular}{|c|c|c|c|}
\hline Parents stress & Yes (\%) & No (\%) & Some-times (\%) \\
\hline \multicolumn{4}{|l|}{ Stress about child dependency: } \\
\hline I'm anxious when I can't care for my child & 55 & 13.3 & 31.6 \\
\hline Autism is a disease can’t deal with it & 55 & 8.3 & 36.7 \\
\hline My child will suffer forever & 51 & 12.3 & 36.7 \\
\hline \multicolumn{4}{|l|}{ Stress about child future: } \\
\hline I worried because my child did not live normally & 52 & 7.3 & 40.6 \\
\hline I worried about what I should do when my child becomes older & 55 & 10 & 35 \\
\hline \multicolumn{4}{|l|}{ Stress about family disharmony: } \\
\hline Taking my child to holidays leading to enjoyment of all family members & 0.0 & 66.7 & 33.3 \\
\hline My child makes me severe sad & 36.7 & 13.3 & 50 \\
\hline My child condition affects my physical \& mental health & 43.3 & 8.3 & 48.3 \\
\hline I become nervous while dealing with my child & 46.7 & 13.3 & 40 \\
\hline I cannot deal with additional financial costs or other needs & 68.3 & 11.6 & 20 \\
\hline \multicolumn{4}{|l|}{ Stress about personal exhaustion: } \\
\hline I cannot do balance between my child needs and others family members needs & 51.3 & 15 & 33.7 \\
\hline Presence of a child with autism leads to negative relationship with my spouse & 41.7 & 8.3 & 50 \\
\hline I feel success when achieving a desirable thing & 58.3 & 16.7 & 25 \\
\hline I feel success when I can learn my child stop undesirable thing & 38.3 & 18.3 & 43.3 \\
\hline I can treat a lot of things in a right way & 23.3 & 26.7 & 50 \\
\hline \multicolumn{4}{|l|}{ Stress about stigma: } \\
\hline I feel severe shame from my child & 54 & 13.3 & 32.7 \\
\hline I avoid meeting my child with family friends or relatives & 26.7 & 30 & 43.3 \\
\hline
\end{tabular}

As it shown on the Figure 1 that, more than half (58\%) of mothers caring for their children with autism were had serious discomfort regarding their psychological well-being. Meanwhile, the minority of them (13\%) were had positive psychological strengths.

Table 6 clarifies that there was a highly statistical significant relation between awareness and psychological well-being among mothers of children with autism.

\section{Discussion}

Raising a child with an autism can be a stressful experience for parents especially when left unmanaged and make their life very hard, usually they are left alone to face the 
stressful challenge of raising a child with autism. ${ }^{[12]}$ In addition, they are also concerned with communication, education and related services, relationships with professionals and the independence of the child and his/her future concerns. ${ }^{[13]}$ Therefore, the aim of this study was to assess the influence of autism awareness on the psychological well-being of mothers caring Parenting a child with Autism is often associated with reduced quality of life, high stress their children with autism.

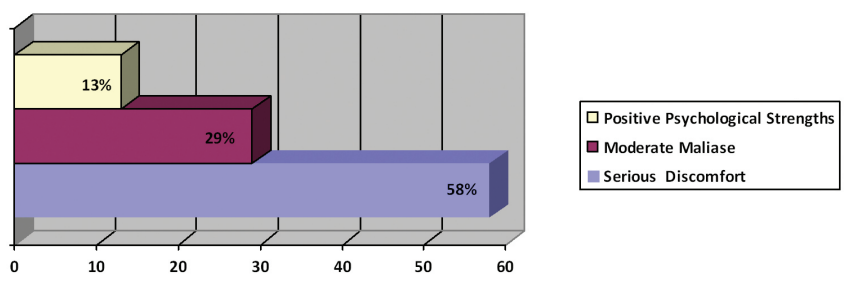

Figure 1. Percentage of total score of psychological wellbeing for mothers caring for their children with autism

Table 5. Psychological wellbeing of mothers caring for their children with autism

\begin{tabular}{|c|c|c|c|c|c|c|c|}
\hline Items & SA(\%) & $A(\%)$ & SLA(\%) & M/NA(\%) & SLD(\%) & $\mathrm{D}(\%)$ & $\operatorname{SD}(\%)$ \\
\hline I lead a purposeful and a significant life & 5 & 8 & 17 & 20 & 5 & 10 & 35 \\
\hline My social relationship is supportive and satisfying & 20 & 9 & 16 & 25 & 15 & 12 & 3 \\
\hline I am engaged and interested in my daily activities & 2 & 3 & 8 & 5 & 12 & 15 & 55 \\
\hline I am contributing to the happiness and well-being of others & 10 & 5 & 10 & 15 & 5 & 5 & 50 \\
\hline I am a competent and capable in the activities that are important to me & 5 & 3 & 2 & 4 & 3 & 13 & 70 \\
\hline I am a good person and live a good life & 6 & 4 & 18 & 52 & 4 & 8 & 8 \\
\hline I am hopeful about my future & 0 & 0 & 2 & 8 & 5 & 15 & 70 \\
\hline People respect me & 68 & 12 & 10 & 5 & 5 & 0 & 0 \\
\hline
\end{tabular}

Note. $\mathrm{SA}=$ strongly agree $\mathrm{A}=$ Agree, $\mathrm{SLA}=$ slightly agree, $\mathrm{M} / \mathrm{NA}=$ Mixed or neither agree nor disagree, $\mathrm{SLD}=$ slightly disagree $, \mathrm{D}=\mathrm{Disagree}, \mathrm{SD}=$ strongly disagree .

Table 6. Impact of awareness on psychological wellbeing for mothers caring for their children with autism

\begin{tabular}{|c|c|c|c|c|}
\hline \multirow{2}{*}{ Items (psychological wellbeing) } & \multicolumn{3}{|c|}{$\begin{array}{l}\text { Awareness of mothers of } \\
\text { children with autism }\end{array}$} & \multirow{2}{*}{$\begin{array}{l}\text { Chi \& } \\
p \text {-value }\end{array}$} \\
\hline & $\begin{array}{l}\text { Poor } \\
(\%)\end{array}$ & $\begin{array}{l}\text { Average } \\
(\%)\end{array}$ & $\begin{array}{l}\text { Good } \\
(\%)\end{array}$ & \\
\hline Serious discomfort: From (0 to 18 ) & 70 & 20 & 10 & $\begin{array}{l}12.99 \\
<.01 *\end{array}$ \\
\hline Moderate malaise: From (19 to 37) & 16.7 & 75 & 8.3 & $\begin{array}{l}7.35 \\
<.01 *\end{array}$ \\
\hline $\begin{array}{l}\text { Positive psychological strengths } \\
\text { From ( } 38 \text { to } 56 \text { ) }\end{array}$ & 13.3 & 20 & 66.7 & $\begin{array}{l}19.62 \\
<.01 *\end{array}$ \\
\hline
\end{tabular}

* Highly significant

\section{Characteristics of children under the study (see Table 1)}

The results of the present study reveal that the age of about two thirds of studied children is from three to five years. This result is agrees with Simsek B, et al. ${ }^{[14]}$ who study the characteristics of parents of children diagnosed with autism and found that half of children with autism ranged from 1-5 years. Meanwhile, this finding is in accordance with that of Wong ${ }^{[15]}$ who mentioned that the autism typically appears in the first 3 years of life.

Concerning to gender of the studied children this study illustrate that, more than half of autistic children are boys, this may be due to there is a genetic factor may affect boys more than girls. This finding is supported with that of Hassan ${ }^{[16]}$ who studied caregivers' awareness regarding autistic children and found that majority of children were boys. This finding was in accordance with Mansour ${ }^{[17]}$ who study the parents' awareness regarding care of their children suffering from autism found that, less than three-fourths of them were males. In addition to that, another study supported by Hayward ${ }^{[18]}$ who point out that, boys are affected with autism more often than girls. Moreover, this finding is supported with Mohamed ${ }^{[19]}$ who study the counseling intervention for parents caring for children with autism and found that that less than three - quarter of the children with autism was males.

The findings of the present study reveals that the ranking of near half of children are the first. This result is in correspondent with Elbahnasawy et al. ${ }^{[20]}$ who found that more than two-thirds of children with autism are boys and two-fifths were ranked as the first child. Similarly, as well, when the birth order of the autistic child was examined, it is ascertained that $43.3 \%$ were the first-born child. This result is supported with the result of Bodier ${ }^{[21]}$ who found that $76.4 \%$ were the first-born child.

The results of the present study indicate that more than onethird of children are in school of special needs while the minority of them is in normal school and the condition presented with a delayed speech in more than one-third of autistic children and about a quarter of them started with a ten- 
dency to play alone. These results are correspondent with El-Baz ${ }^{[22]}$ who study the risk factors for autism: An Egyptian study, and found that one- third of cases (36\%) are in the school of special needs and $9 \%$ are in normal school without shadow, the condition presented with delayed speech in $72 \%$ and in $11 \%$ started with tendency to play alone.

\section{Socio-demographic characteristics of mothers under study (see Table 2)}

The results of this study show that the age of studied mothers are ranged from 20 to less than 30 years is constitute more than half and more than two-thirds of them have a moderate level of education. And, there is two- third of the studied mothers are not working and have insufficient monthly income. As well, seventy percent of them reside in the urban area and had no consanguinity. This finding is in agree with El Sawy ${ }^{[23]}$ who study some environmental and genetic determinants of autism in Egyptian children, and found that $81.8 \%$ of mothers in the cases were between age group 20 to 30 . and found that, maternal occupation was highly demonstrated in the sample were housewives and constitute a highest proportion of the studied groups which reside in the urban area.

On the other hand this result is not agree with Attiya ${ }^{[24]}$ who studied the effect of training program for parents of autistic children in changing their negative attitudes toward their autistic children and found that, most age of the mothers were ranged between 31-38 years, and found in his study that, more than half were housewives and living in the urban areas.

Regarding education, the results of the present study reveal that more than half of studied mothers are moderately educated. This may be due to the low socio-economic status of mothers who have not completed higher education and they prefer to stay at home to take care of her child also, also as results of their responsibility to spend a part of their effort and time on the care and follow-up of their children with autism. This finding was in agreed with Seif Eldin ${ }^{[25]}$ who found that nearly one third of mothers' were secondary school and the highest percentages of mothers were housewives. Moreover, this result was supported by Mohammed et al. ${ }^{[26]}$ who reported that more than one-third of the caregivers of autistic child were illiterates. Another study carried out by Guan ${ }^{[27]}$ who found that $71.7 \%$ of mothers of theautistic children were illiterates. Similarly, this finding is in congruence with Ah$\operatorname{mad}$ et al. ${ }^{[28]}$ who reported that the majority of mothers of autistic child were housewives.

As regards to monthly income, this study revealed that near the two-thirds of mothers are haven't sufficient monthly in- come. This result could be due to the high cost of medical care in developing countries as Egypt which make a burden on the family budget. These results are supported by Mendoza et al. ${ }^{[29]}$ they study the economics of the autism in Egypt, they discovered that autism costs in Egypt largely derive from much higher investments in time, attention and behavioral adaptation on the part of family care givers. This analysis was also supported by a study carried out by Ghanizadeh et al. ${ }^{[30]}$ In this respect, they mentioned that parent with the autistic child more likely have financial problems and they need additional income for the cost of child's medical care. The cost for caring for the children with the autism is more than twice of children without autism.

Finally, the findings of this study are confirmed by the results of Amr ${ }^{[31]}$ who study the socio-demographic factors in Arab children especially in Egypt and Jordan and found that most of them belonged to families of low socioeconomic standards with unsatisfactory income.

\section{Percentage distribution of mothers' awareness regard- ing their knowledge about autism (see Table 3)}

The results of this study reveal that more than two thirds of the studied sample are poor in knowledge regarding autism. This results may be due to lack of media awareness about autism and how to care and deal with it. In addition, the mothers may be occupied by her responsibilities in their homes and with their other children and didn't have time to read about the disease. These results are supported by other research findings ${ }^{[32]}$ who study the knowledge on the care of autistic child among the mother's in Dhaka, and found that the respondents showed overall poor knowledge among mothers about autism. ${ }^{[33]}$ who found that only a few percent of parents were aware of the autism whereas the majority of them did not hear about it. Moreover, Ref. ${ }^{[34]}$ reported that the minorities of parents were scored good knowledge regarding concept of autism, help parents with autistic children in preschool to deal effectively with behavioral problems for autistic children and understand their disability, hence increase awareness of parents about autism to be able to care for their children.

\section{Mothers' stress regarding care of their children with autism (see Table 4)}

The results of the present study clarify that parent stress regarding the child dependency are common among more than half of the mothers under study that they feel anxious when they can't care for their child in addition to that they mentioned that autism is a disease can't deal with it and will suffer forever. This may be due to the fact that autism considers a severely disabling disorder. Problems as the absence 
of language, anti-social behaviors and tantrums are likely to produce high levels of stress for parents caring autistic children for many years. This result are confirmed by Bristol ${ }^{[35]}$ who stated that, parents' stress results from child dependency and failure to understand an autistic child's language, both are felt frustrated and the child can often be a tantrum.

Furthermore, our study find that the majority of parents have a stress about their children with autism future. They worried because their children did not live normally and asking about what they should do when the child becomes older. This may be due to the majority of children need partial or complete assistance in performing the daily activity, few children with autism are ever able to live and work independently, in addition to that caring for the child with autism requires a great deal of time, routine, energy, and money, and also it may be due to their children dependently especially in their activity of daily living, set aside funds, sought useful resources, and trained the autistic child's siblings or other family members to take care of the child. Some parent participants explain the autistic child condition to their other children and family members and expected them to help care for the autistic child. Furthermore, some even expected the siblings to bear the responsibility of taking care of the autistic child after the parents could no longer do so. These findings are consistent with Shu et al. ${ }^{[36]}$ and Rivers et al. ${ }^{[37]}$ who reported that, parents of autistic children were concerned about their children's future, education and daily living arrangements for, as well as their needs for social support.

Concerning to stress about personal exhaustion, the result of the present study revealed that the majority of the parent suffering from personal exhaustion regarding caring their children with autism. They mentioned that the child condition affects their physical \& mental health and they become nervous while dealing with their child. This may be due symptoms of autism produced parental distress. Caring was exhausting for their parents, and the constant crying and screaming made parents tense and led them to frequent arguments. These difficulties caused their parents to doubt their abilities. This explanation is supported by Johnston, ${ }^{[38]}$ who reported that autistic child's deficits are stressful for parents. Parents lacking appropriate leisure skills often require constant structure of their time, a task not feasible to accomplish in the home environment. Many families struggle with the additional challenges of getting their child to sleep through the night or eat a wider variety of foods. All of these deficits and behaviors are physically exhausting for parents and emotionally draining. Ref. ${ }^{[39]}$ was in the same line that he was assessed the impact of maternal, child and family characteristics on their daily well-being and parental experiences of mothers caring for their children with autism and suggested

Published by Sciedu Press that such families are at greater risk for numerous difficulties (e.g., marital, emotional, and physical problems) than families with non-autistic children.

In relation to mothers' stress about family disharmony, the result of the current study indicated that about half of them cannot do a balance between their children needs and others family members needs and cannot treat a lot of things in a right way, in addition to that a negative relationship with the spouse. Because many children with autism have destructive behavior, the effort of such behavior on parents and personal effects may be a source of stress. Maintaining a tidy house is almost impossible under such circumstances, and many homes with autistic children display evidence of their detective tendencies, as damaged walls, discolored carpets and the presence of only the most strong and inexpensive furniture. caring electronic apparatus such as television and a computer is especially difficult. Added to that, the mother takes on the majority of the care giving duties related to the child with autism, then the other children may receive less attention. In addition, the mother may have little time for herself or her husband because of the increased amount of care giving a time that a child with autism requires. This result and analysis were supported by a study carried out by Wiener ${ }^{[40]}$ who found support for the idea that caring for a child with autism takes more effort and time more than any child. This result is similar to that of Tunali et al. ${ }^{[41]}$ who found that mothers caring their children with autism were much harder to care for than most children of their age without autism. In relation to the relationship with the spouse the result of the present study is agreement with Kuhn et al. ${ }^{[42]}$ who found that parents of children with autism are at a high risk for marital conflict.

Unfortunately concerning the parent stress about stigma, it was found that the majority of them feel stigmatized by their child with autism; they feel severe shame from their children and avoid meeting their children with family friends or relatives. This may be due to stigma which is one of the most difficult aspects of public encounters experienced by parents with the autistic child. Autism is often accompanied by extremely disruptive antisocial behavioral although the problem with language, for example, are common characteristic of the disorder, more troublesome symptoms as self-destructive act are also frequently associated with it. This analysis was congruent with a study ${ }^{[43]}$ who pointed to that fear of being stigmatized for having a child with autism can prevent the family from looking for help and or sharing their experiences with other families of children with autism. This finding has an agreement with an assumption of much research on the stigma that shows that parents are the victims of a courtesy of stigma because of their children with autism. ${ }^{[44]}$ 
Psychological wellbeing of mothers caring for their children with autism (see Table 5)

It is obvious from this study that small percent of studied mothers are strongly agreed about they lead a purposeful and significant life, they engaged and interested in their daily activities, they actively contribute to the happiness and wellbeing of others, they are competent and capable in the activities that are important to them, they are good person and live a good life, they are hopeful about their children's future, while about quarter of them were strongly agree that their social relationships are supportive, satisfying and feel pessimistic about their children future, in addition to more than two third of them were strongly agree that people respect them. These results confirm the earlier findings, which report that parents of children with disabilities have more stress than parents of children without disabilities. This finding is supported by Abbeduto et al. ${ }^{[45]}$ who noticed that mothers of children with autism were more pessimistic about their children's future. This result is confirmed by Yirmiya et al. ${ }^{[46]}$ who mentioned that there was a strong evidence that parents of children with autism face a high level of stress. Meanwhile, this result was also in accordance with Watinikmat ${ }^{[47]}$ who investigate the prevalence of parental stress and psychological well-being among parents of children with autism and found that a high proportion of parents were stressed up and more than half of them showed poor psychological well-being .

This result is also supported with Seltzer et al. ${ }^{[48]}$ who reported that mothers of children with ASD experience lower level of well-being than mothers of children without disabilities and/or with other disabilities. Moreover, Hayes et al. ${ }^{[49]}$ added that, parents of children with autism tend to report lower quality of life, more depression, and greater pessimism about their children's future than parents of other developmental disabilities. And Almansour ${ }^{[50]}$ evaluate the presence of depression and anxiety in parents/caregivers of autistic children and found that parents of children with autism were more susceptible to negative psychological outcomes and frequently experience an excessive set of difficulties and otherwise maintaining a normal family life and adversely affects their psychological wellbeing.

\section{Impact of awareness on psychological wellbeing among} mothers caring for their children with autism (see Table 6)

The result of the present study clarifies that there is a highly statistical significant relation between awareness and psychological well-being among mothers of children with autism. This could be due to the mothers who have a lack of awareness about autism suffering from negative psychological well-being and serious psychological discomfort. Mothers did not initially report a concern about the children with autism because they accepted their behavior as a part of their age and did not consider it to be symptomatic of any particular disorder and it's attributed to their lack of awareness in society. In addition to the lack of awareness of mothers make them not able to get expose of various remedial measures which could help them to bring improvement in the condition of the child.

\section{Conclusion}

The study concluded that about two third of the studied sample had poor awareness regarding their knowledge about autism and there was a highly statistical significant relation between awareness, stress and psychological well-being of mothers of children with autism.

\section{RECOMMENDATIONS}

Based upon the finding of the current study, the following recommendations can be deduced:

(1) Counseling parents to enhance parents awareness about autism for modifying their behaviors and psychosocial skills.

(2) Developing free educational resources about autism for parents at home, at school, with teachers and students about how to deal with autism.

(3) Media awareness to help mothers in prompt tolerance and understanding autism with a clear explanation.

(4) Establish special schools for autistic children in different provinces in Egypt to help parents in caring for their children with autism in a scientific way and decrease their burden.

(5) There is a need for more research on the psychosocial well-being of the parents/caregiver of children with autism.

\section{CONFlicts OF INTEREST Disclosure}

The authors declare that there is no conflict of interest.

\section{REFERENCES}

[1] Murshid E. Diet, Oral Hygiene Practices and Dental Health in Autistic Children in Riyadh, Saudi Arabia. OHDM. 2014; 13(1): 91-96.
[2] Stevens M. Prevalence of the autism disorders in multiple areas of the united states. Journal of Research. 2007; 12: 112-122.

[3] Pisula E. Parenting Stress in Mothers and Fathers of Children with 
Autism Spectrum Disorders, A Comprehensive Book on Autism Spectrum Disorders, phildelphia; 2011. 559 p.

[4] Mak W, Kwok Y. Internalization of stigma for parents of children with autism spectrum disorder in Hong Kong. J of Social Science \& Medicine. 2010; 70: 2045-2051. PMid:20362379. http: //dx.doi.org/10.1016/j. socscimed.2010.02.023

[5] Kamei A. Perception and experiences of mothers who have children with autism spectrum disorders: cross-cultural studies from the US and Japan. A Dissertation Submitted to the Faculty of the Graduate School at the University of North Carolina at Greensboro in Partial Fulfillment of the Requirements for the Degree Doctor of Philosophy; 2013. 35 p.

[6] Dehnavi S, Malekpour M. The Share of Internalized Stigma and Autism Quotient in Predicting the Mental Health of Mothers with Autism Children in Iran. International Journal of Business and Social Science. 2011; 2(20): 251-259.

[7] Petrongolo M. Stress in Mothers of Newly Diagnosed Children with Autism Spectrum Disorders: Barriers to Care, Use of Support Services, and Child Behavior. PCOM Psychology Dissertations. Philadelphia; 2014. 300 p.

[8] Afifi M. Mental health publications from the Arab world cited in Pub-Med, 1987-2002. East Mediterr Health J. 2005; 11(3): 319-28.

[9] Haffiz M. Study about problem size of autism in Egypt. Pediatric Medicine, National Commission for Childhood, Studies and Research Forum; 2007. 98 p.

[10] Al-Farsi Y, Al-Sharbati M. Brief Report: Prevalence of Autistic Spectrum Disorders in the Sultanate of Oman. J Autism Dev Disorder. 2011; 41: 821-5. PMid:20809376. http://dx.doi.org/10.1007 /s10803-010-1094-8

[11] Diener E. New measures of well-being: Flourishing and positive and negative feelings. Social Indicators Research. 2009; 39: 247-266. http://dx.doi.org/10.1007/978-90-481-2354-4_12

[12] Anderson A. Mindfulness stress and wellbeing in parent of child with autism: Systematic review. Journal of Child and Family Studies. 2016; 25: 1-14.

[13] Matson J, Kozlowski M. The increasing prevalence of autism spectrum disorders. Research in Autism Spectrum Disorders. 2011; 5(1): 418-425. http: //dx.doi.org/10.1016/j.rasd.2010.06.004

[14] Simsek B, Koroglu Y. A study on the demographical characteristics of parents with children diagnosed with autism, problem they face and their knowledge on alternative treatment methods. Procedia - Social and Behavioral Sciences. 2012; 47: 577-585. http://dx.doi.org/10.1016/j.sbspro.2012.06.699

[15] Wong A. Nursing care of infants and children, (8th ed.), USA; 2007. p. 1021-1022.

[16] Hassan L. Caregiver's awareness regarding autistic children, Master Thesis, Faculty of Nursing, Community Department, Ain Shams University; 2008. p. 82-85.

[17] Mansour K. Parent awareness regarding care of their children suffering from autism. Unpublished master's thesis, university of Ain Shams, Cairo, Egypt; 2010. p. 33-35.

[18] Hayward H. Assessing Progress during Treatment for Young Children with Autism Receiving Intensive behaviors; 2011. p. 45-49. Available from: http://aut.sagepub.co.ok/journalpermiss ions'nav

[19] Mohamed E. Counseling intervention for parents caring for children with autism. Published doctorate thesis, University of Ain Shams, Cairo, Egypt; 2012. p. 55-62.

[20] Elbahnasawy T, Girgis M. Counseling of Mothers to Cope with their Children autism. Journal of Psychology. 2011; 7(7): 187-192.

[21] Bodier C. Prevalence of pervasive developmental disorders - A review. L'Encephala. 2009; 35: 36-42.
[22] El-Baz F. Risk factors for autism: An Egyptian study. The Egyptian Journal of Medical Human Genetics. 2011; 12: 31-38. http: //dx.doi.org/10.1016/j.ejmhg.2011.02.011

[23] El Sawy M. Study of Some Environmental and genetic determinants of autism in Egyptian children. International Journal of Psychology and Counseling. 2011; 3(8): 130-136.

[24] Attiya O. The efficiency of training program for parents of autistic children in changing their negative attitudes toward their autistic children. Doctorate Thesis. Psychology Department, Faculty of Arts, Ain Shams University; 2006. p. 221-225.

[25] Seif Eldin A. Use of M-CHAT for a multinational screening of young children with autism in the Arab countries. International Rev Psychiatry. 2008; 20(3): 281-289.

[26] Mohammed M, Ayesha N, Farah A. Awareness of Autism in Primary School Teachers, Autism Res Treat. 2013; 9(6): 1595.

[27] Guan V. Parental quality of life in autism spectrum disorder: Current status and future direction. Actapsychopathol. 2016; 2(1): 112-123.

[28] Ahmad G, Mohammad J, Hamid A. Helping Families for Caring Children with Autistic Spectrum Disorders. Arch. Iranian Med. 2009; 12(5): 478-482.

[29] Mendoza L, Hill C. The Economics of Autism in Egypt. American Journal of Economics and Business Administration. 2010; 2(1): 12-19. http://dx.doi.org/10.3844/ajebasp. 2010.12.19

[30] Ghanizadeh A, Alishahi M, Ashkani H. Helping Families for Caring Children with Autistic Spectrum disorders. Archives of Iranian Medicine. 2009; 12: 478-482.

[31] Amr M. Socio-demographic factors in Arab children with Autism Spectrum Disorders. The Pan African Medical Journal. 2012; 13: 65.

[32] Parvin M. Knowledge on Care of Autistic Child among the Mother's Attending Protibondhi Foundation. Journal of Medical Science Dhaka. 2015; 14(2): 179-183.

[33] Bashir A. Awareness and Problems of Parents of Children with Autism Spectrum Disorders. International Journal of Interdisciplinary Research and Innovations. 2012; 2(2): 42-48.

[34] Khushabi K. Coping Strategies and Stress in Mothers with Autistic Children in Comparison with Mothers with Normal Children. Journal of Family Research. 2011; 6(1): 87-97.

[35] Bristol M. Mothers of children with autism or communication disorders: successful adaptation and the double ABCX model. Journal of Autism and Development Disorders. 2010; 17: 469-86. http://dx.doi.org/10.1007/BF01486964

[36] Shu B, Hsieh S. Toward an understanding of Mothering: The caregiving Process of mothers with autistic child. Journal of Nursing Research. 2009; 9: 202-213.

[37] Rivers J, Stoneman Z. Siblings Relationships When a Child has Autism: Marital Stress and Support Coping. Journal of Autism and Developmental Disorders. 2010; 33: 383-394.

[38] Johnston E. Stress in UK families conducting intensive home-based behavioral intervention for their young children with autism and Down syndrome. Journal of Autism Disorder. 2010; 31: 327-36.

[39] Willis K. The impact of maternal, children and family characteristics on daily wellbeing of parents experience of mother caring a child with autism, Texas Christian University. USA. Journal of Psychology Development. 2016; 13: 68.

[40] Wiener C. The burden of autism. In Strauss, A. et al, (eds.) Chronic Illness and the Quality of Life (2nd edition) St. Louis: The C.V. Mosby Company; 2010. 665 p.

[41] Tunali B, Power T. Coping by redefinition: Cognitive appraisals in mothers of children with autism and children without autism. Journal of Autism and Developmental Disorders. 2009; 32(1): 25-34. 
[42] Kuhn C, Carter S. Maternal self-efficacy and associated parenting cognitions among mothers of children with autism. Topics in Early Childhood Special Education. 2010; 18: 144-159.

[43] Wand P. Stresses and Coping Strategies of Chinese Families with Children with Autism and Other Developmental Disabilities. Journal Autism Dev Disorder. 2011; 41: 783-795. PMid:20859670. http://dx.doi.org/10.1007/s10803-010-1099-3

[44] David E. Perception of Stigma: The Parents of Autistic Children. Sociology of Health. 2009; 15(1): 102-120.

[45] Abbeduto L, Seltzer M, Shattuck P, et al. Psychological well-being and coping in mothers of youths with autism, Down syndrome, or fragile X syndrome. American Journal on Mental Retardation. 2004 109(3): 237-254. http://dx.doi.org/10.1352/0895-8017(20 04) $109<237:$ PWACIM $>2.0$. CO ; 2

[46] Yirmiya N, Shaked M. Psychiatric disorders in parents of children with autism: a meta-analysis. J Child Psychol Psychiatry. 2005; 46: 69-83. PMid:15660645. http://dx.doi.org/10.1111/j.1 469-7610.2004.00334.x
[47] Watinikmat A. Stress and psychological wellbeing among parents of children with autism spectrum disorder. ASEAN Journal of Psychiatry. 2008; 9(2): 65-72.

[48] Seltzer M, Greenberg J, Hong J, et al. Maternal cortisol levels and behavior problems in adolescents and adults with ASD. Journal of Autism \& Developmental Disorders. 2010; 40(4): 457469. PMid:19890706. http://dx.doi.org/10.1007/s10803-0 09-0887-0

[49] Hayes A, Watson L. The impact of parenting stress: a meta-analysis of studies comparing the experience of parenting stress in parents of children with and without autism spectrum disorder. Journal of Autism and Developmental Disorders. 2013; 43(3): 629642. PMid:22790429. http: //dx . doi .org/10.1007/s10803-0 $12-1604-\mathrm{y}$

[50] Almansour M. Depression and anxiety among parents and caregivers of autistic spectral disorder children. Neurosciences. 2013; 18(1): 58-63. 